\title{
AVALIAÇÃO EXPERIMENTAL DO TEOR DE UMIDADE RESIDUAL EM MATERIAL SÓLIDO RETIDO SOBRE A TELA DE PROTÓTIPO DE PENEIRA VIBRATÓRIA
}

\author{
M. E. D. SILVA ${ }^{1}$, R. M. SILVA ${ }^{1}$, T. O. ABDALA ${ }^{1}$, F. S. GUERREIRO ${ }^{2}$ e R. GEDRAITE ${ }^{3}$
}

${ }^{1}$ Bolsista PIBIC-CNPq/UFU, discente do curso de Engenharia Química

${ }^{2}$ Bolsista PPGEQ/UFU, discente do curso de Mestrado em Engenharia Química

${ }^{3}$ Professor da Faculdade de Engenharia Química da UFU/MG

E-mail para contato: rgedraite@,feq.ufu.br

\begin{abstract}
RESUMO - Este artigo apresenta uma contribuição acerca da investigação experimental sobre o emprego do adimensional referente à força-g sobre o teor de umidade residual do material sólido retido sobre tela de protótipo de peneira vibratória de abertura 99 microns (175 mesh). O estudo foi conduzido tendo por base o processo tradicionalmente empregado em unidades de controle de sólidos em perfuração de poços de petróleo. Foi definida e montada a malha de controle do adimensional de força-g, tendo sido escolhida como variável de processo manipulada a rotação imposta aos motovibradores instalados na peneira vibratória. Foi realizado experimento utilizando uma bancada experimental para coletar dados de processo referentes às variáveis consideradas. Os resultados obtidos sugerem que um aumento no valor do adimensional de força-g não necessariamente contribui para diminuir o teor de líquido residual arrastado com o material sólido retido.
\end{abstract}

\section{INTRODUÇÃO}

O tratamento de fluido de perfuração é de suma importância na operação de perfuração de poços de petróleo, sob o ponto de vista operacional, ambiental e econômico. Este fluido possui sólidos em suspensão que têm origem na ação de corte das formações rochosas pela broca de perfuração ou em sua formulação inicial, sendo classificados, de acordo com os seus componentes base, em fluidos aquosos e não aquosos. As propriedades físicas deste fluido devem ser monitoradas e corrigidas para carrear os cascalhos até a superfície; manter a estabilidade mecânica do poço; resfriar a broca; transmitir força hidráulica até a broca; manter os cascalhos em suspensão quando sem circulação; lubrificar a coluna de perfuração entre outros. Os equipamentos utilizados para a separação sólido-líquido em uma unidade típica de controle de sólidos são divididos em três grupos sequenciais: peneiras vibratórias, bateria de hidrociclones (desareiadores e dessiltadores) e centrífuga decantadora (Lobato et al, 2011).

Um dos métodos mais empregados para remoção de sólidos presentes no fluido de perfuração é fazer o mesmo escoar através de uma tela em vibração. Partículas menores que a abertura da tela passarão juntamente com o fluido. Partículas maiores serão separadas e encaminhadas para possível secagem e posterior descarte. O propósito da vibração é o transporte do cascalho para fora da tela e o aumento da capacidade de processamento de 
líquido. Esta ação causa uma rápida separação, reduzindo a quantidade de líquido perdido com os sólidos (Raja et al, 2012; Guerreiro et al, 2013).

O objetivo deste trabalho foi avaliar experimentalmente a influência do adimensional força-g sobre o teor de umidade arrastado juntamente com os sólidos separados em protótipo de peneira vibratória equipado com tela de 175 mesh.

\section{MATERIAIS E MÉTODOS}

Foi utilizada como base para o desenvolvimento dos modelos apresentados neste trabalho a unidade experimental mostrada na Figura 1, a qual é formada por uma peneira vibratória com 1,65 m de comprimento, $0,81 \mathrm{~m}$ de largura e $1,0 \mathrm{~m}$ de altura, equipada com dois motovibradores e uma tela de separação, podendo esta última ser trocada quando necessário; um tanque de $500 \mathrm{~L}$ com agitação para alimentação da suspensão à peneira; um tanque de descarga de $200 \mathrm{~L}$ para coleta do material passante e uma bomba centrífuga para transportar este líquido que passa pelas aberturas da tela de volta ao tanque de alimentação.

Figura 1 - Unidade de recuperação de fluido de perfuração

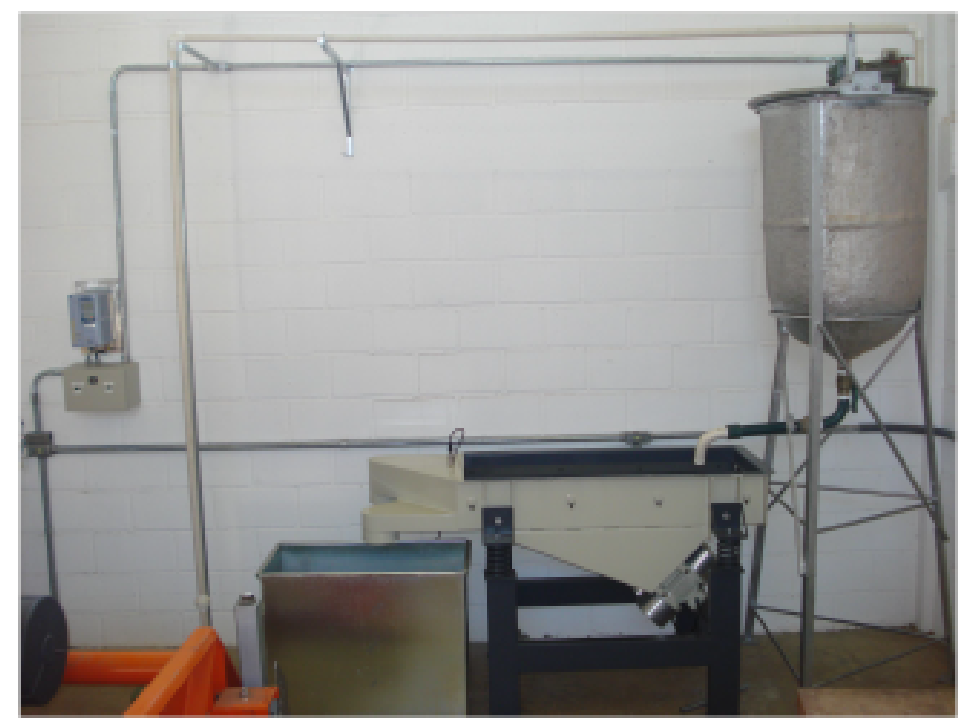

A peneira está equipada com dois motovibradores com $0,75 \mathrm{cv}$ de potência cada um. Esses foram montados de maneira a gerar movimentos em sentidos opostos de forma a garantir a vibração adequada da peneira, impondo movimento linear ao material alimentado sobre a tela de peneiramento. Para controlar o valor da intensidade da vibração imposta ao sistema, ajustou-se a frequência de rotação dos motovibradores por meio de um inversor de frequência da marca WEG modelo CFW700. A vibração imposta à tela da peneira foi medida por meio de acelerômetro piezelétrico da marca PCB Piezoeletronic modelo 646B00, o qual foi responsável por enviar um sinal na faixa de 4 a 20 mAcc a uma placa de aquisição de dados da National Instruments modelo USB 6008. Foi utilizado o software Labview 2013 da National Instruments para a coleta de dados e monitoramento da unidade experimental (Garcia, 2005; Liu; Gao, 2012). 
Foram preparados $159 \mathrm{~L}$ de suspensão de rocha fosfática solubilizada em água, na concentração de $1 \%$ em volume. A alimentação da suspensão era realizada abrindo-se a válvula manual do tanque principal de alimentação para alimentar a suspensão sobre uma calha de aço inoxidável visando distribuir o material uniformemente sobre a largura da tela da peneira. A peneira usou tela de 175 mesh. Depois de esgotada toda a suspensão do tanque de alimentação principal, o material retido era coletado e devidamente pesado em uma balança analítica, e o material passante era recolhido no tanque de coleta. O valor da massa total de material retido foi usado para o cálculo da eficiência do peneiramento através do balanço de massa. Ainda em relação a este material, três amostras eram separadas para a avaliação do teor de umidade, realizada por pesagem, após submeter o material coletado à secagem em estufa a $105^{\circ} \mathrm{C}$ por 24 horas.

Após a coleta de amostras para análises, os sólidos utilizados no peneiramento eram retornados para o tanque principal de alimentação, manualmente, e o líquido era retornado através de uma bomba centrífuga localizada na saída do tanque de coleta. $\mathrm{O}$ experimento foi conduzido para o valor do adimensional de força-g, imposto à tela da peneira vibratória, igual a 1,0 e concentração volumétrica da suspensão igual a $1 \%$.

\section{RESULTADO E DISCUSSÃO}

$\mathrm{Na}$ Figura 2 é apresentado o comportamento temporal do número adimensional correspondente à força-g em resposta a variação em degrau de amplitude $1092 \mathrm{rpm}$ na frequência dos motores de acionamento dos motovibradores.

Figura 2 - Resposta do adimensional de força-g a uma variação em degrau aplicada na frequência dos motovibradores

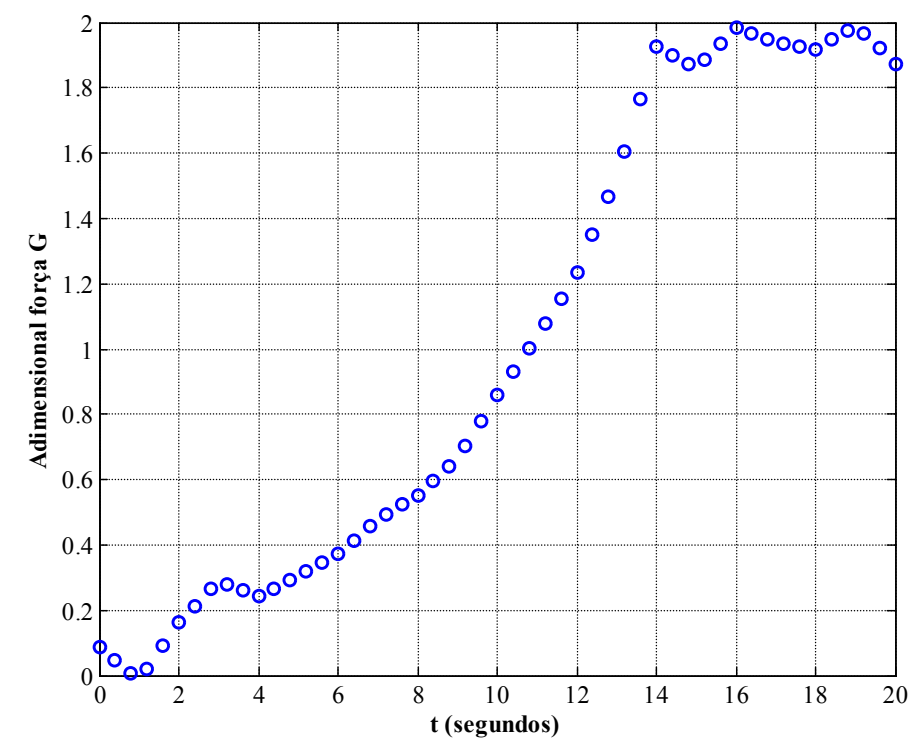

O comportamento temporal da variável de processo teor de umidade arrastado juntamente com os sólidos separados em função do número adimensional que caracteriza a força-g aplicada, para a peneira vibratória estudada e considerando a concentração 
volumétrica de sólidos de 1\%, é apresentado na Figura 3. Na Figura 4 é apresentado o diagrama de simulação correspondente (Garcia, 2005).

Figura 3 - Resposta do teor de umidade nos sólidos separados à variação da amplitude do sinal do adimensional de força-g

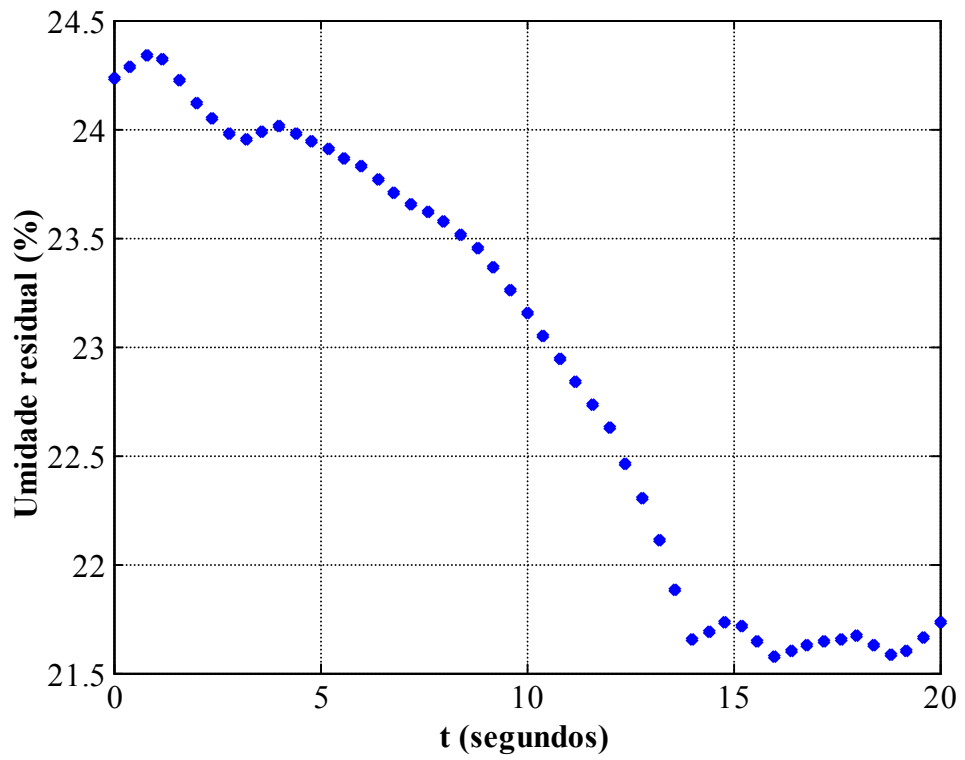

Com base nos resultados obtidos, verificou-se que à medida que o valor do adimensional de força-g aumentou, até alcançar a nova condição de estado estacionário, o teor de umidade residual diminuiu. Este comportamento era esperado, uma vez que a vibração deveria - de fato - proporcionar uma maior remoção de liquido residual presente.

Figura 4 - Diagrama de simulação do teor de umidade nos sólidos separados à variação da amplitude do sinal do adimensional de força-g

$$
\mathrm{Cv}=1 \%
$$
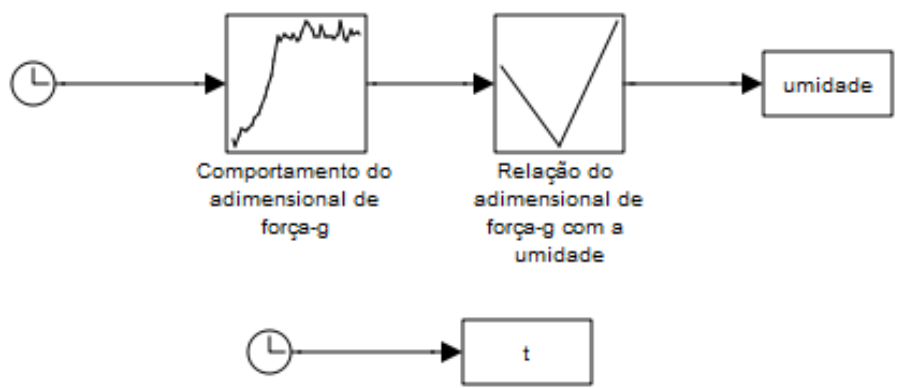

\section{CONCLUSÃO}


Considerando os resultados obtidos no experimento apresentado, pode-se concluir que o aumento da amplitude do adimensional da força-g contribuiu para diminuir o teor de umidade residual presente no material sólido retido sobre a tela da peneira para a concentração volumétrica da suspensão igual a $1 \%$.

Com base no aprendizado obtido neste trabalho, pretende-se desenvolver em etapa posterior o modelo matemático dinâmico identificado do comportamento do teor de umidade residual, com base em experimentos propostos futuramente especificamente para tal finalidade, os quais poderão ser usados como ferramenta de análise de processo.

Com base no modelo identificado, poder-se-á avaliar o impacto que alterações préestabelecidas no valor da força-g teriam sobre o teor de umidade arrastado pelo material sólido particulado retido sobre a tela da peneira.

O principal benefício que poderá resultar da aplicação do modelo no processo está relacionado ao melhor controle da operação, minimizando a perda de fluido de perfuração o caso específico de poços e petróleo e maximizando a vida útil da tela da peneira.

\section{AGRADECIMENTOS}

Os autores agradecem à UFU, ao CNPq e à PETROBRÁS pelos recursos concedidos e apoio em pesquisas no projeto referente ao termo de cooperação $\mathrm{N}^{\mathrm{o}} 0050.0078502 .12 .9$.

\section{REFERÊNCIAS}

GARCIA, C. Modelagem e Simulação de Processos Industriais e de Sistemas Dinâmicos. 2005. EDUSP, São Paulo.

GUERREIRO, F. S., QUEIROZ, C. G., NEIRO, S. M. S., SÁ, C. H. M., GEDRAITE, R. (2013). Contribution to the study of dynamic behaviour of a shale shaker typically used in drilling fluid treatment unit. Anais do V Encontro Nacional de Hidráulica de Poços de Petróleo e Gás, Teresópolis - RJ, 5 a 8 de agosto de 2013.

LIU, T.; GAO, F.(2012). Industrial Process Identification and Control Design. SpringerVerlag, London - UK.

LOBATO, F. S., OLIVEIRA-LOPES, L. C., GEDRAITE, R., NEIRO, S. M. S., MURATA, V. Identificação de modelos para unidades de recuperação do fluido de perfuração. In: IV Encontro Nacional de Hidráulica de Poços de Petróleo e Gás, Foz do Iguaçu - PR, 2011.

Raja, V., Chase, G. G., Jones, B. N. and Geehan, T. (2012). Computational Modeling and Experiments on Shale Shaker Performance. Proceedings of AADE Fluids Technical Conference and Exhibition. Houston, Texas. 